\title{
Where Does Interventional Radiology Fit in with Trauma Management Algorithm?
}

\author{
A. S. Pillai, BS ${ }^{1} \quad$ S. Srinivas, BS ${ }^{1} \quad$ G. Kumar, MD $\quad$ A. K. Pillai, MD \\ 1 University of Texas, Medical Branch Galveston, Galveston, Texas \\ 2 Southwestern Medical Center, University of Texas, Dallas, Texas \\ Address for correspondence A. K. Pillai, MD, University of Texas, \\ Southwestern Medical Center Dallas, TX 75390 \\ (e-mail: anil.pillai@utsouthwestern.edu).
}

Semin Intervent Radiol 2021;38:3-8
Abstract
Keywords
- trauma
- hemorrhage
- embolization
- algorithm
- interventional radiology

Trauma is a major cause of death in the United States, particularly in the younger population. Many traumatic deaths, as well as major morbidity, occur secondary to uncontrolled hemorrhage and eventual exsanguination. Interventional radiology plays a major role in treating these patients, and interventional techniques have evolved to the point where they are an integral part of treatment in these critically ill patients. This article reviews the role of interventional radiology in the treatment algorithms for traumatic injury sponsored by major societies and associations.
Trauma is the leading cause of death in people aged 45 years and younger, accounting for $10 \%$ of deaths globally per year. Exsanguination is the major cause of preventable mortality. ${ }^{1}$ In the management of the severely injured and bleeding patient, the cornerstone is represented by early detection and aggressive management of hemorrhage. Uncontrolled hemorrhage results in trauma-induced coagulopathy which is responsible for more than half of the deaths within the first 48 hours after hospital admissions. ${ }^{2}$

Interventional radiology (IR) is part of the nonoperative management (NOM) algorithm for a trauma patient. Conventional role of IR endorsed by most guidelines includes management of patients who are hemodynamically stable. The World Society of Emergency Surgery (WSES) guidelines define hemodynamic instability in an adult patient as admission systolic pressure ${ }^{3}$ :

$<90 \mathrm{~mm} \mathrm{Hg}$ with clinical evidence of hemorrhagic shock. $>90 \mathrm{~mm} \mathrm{Hg}$ but requiring bolus infusions/transfusions and/or vasopressor drugs and/or admission base excess greater than -5 mmole/L or transfusion requirement of $\geq$ 4 units of packed red blood cells within the first 8 hours.

Increasing availability of equipment and resources is shifting the role of endovascular management in trauma to hemodynamically unstable patients especially in surgically difficult areas like pelvic trauma (PT). ${ }^{4}$ According to the American College of Surgeons Committee on Trauma (ACS-
COT), the IR team should be available to perform procedure within 30 minutes in level I and level II trauma centers in this low-volume but high-risk patient population. ${ }^{5}$ The Society of Interventional Radiology (SIR) position statement for endovascular interventions in trauma requires the IR team to be ready within 60 minutes from the time the decision to proceed with angiography. In addition, SIR recommends that an angiography suite must be available 24/7. In facilities without a 24-hour angiography suite, a protocol should be in place to postpone elective procedures during trauma activation. An algorithm for trauma activation should be created for each trauma scenario in a multidisciplinary approach. ${ }^{6}$

In cases of pediatric trauma, management is more complex due to the specific nature of care. In institutions that are not pediatric trauma centers, pediatric care should adhere to the same algorithm as the adult population. Currently, there is only one evidence-based guideline on management of pediatric trauma, specifically on the management of blunt renal trauma. ${ }^{6}$ The development of evidence-based clinical practice guidelines is an area of ongoing research.

\section{Creating an Institutional Trauma Protocol for IR Activation and Response}

Several studies have observed that delays in IR response times are linked to poor patient outcomes. ${ }^{7-9}$ The common denominator in these studies is the absence of an
Issue Theme Seminars in IR Trauma; Guest Editors, Patrick D. Sutphin, MD, PhD and Sanjeeva Kalva, MD (c) 2021. Thieme. All rights reserved. Thieme Medical Publishers, Inc., 333 Seventh Avenue, 18th Floor, New York, NY 10001, USA 
institutional protocol for multidisciplinary collaboration. Multiple studies have demonstrated the value of a multidisciplinary institutional protocol in reducing mortality after PT. ${ }^{10,11}$ For instance, Chen et al demonstrated a 10 -year experience before and after implementing an institutional protocol involving trauma surgeons, orthopaedic surgeons, interventional radiologists, and intensive care specialists. The annual mortality rate in patients who sustained unstable pelvic fractures with an injury severity score (ISS) $\geq 5$ decreased from 7.8 to $2.4 \%{ }^{11}$ The SIR recommends institutional trauma protocols based on available resources. The ACS-COT requires an interventional radiologist to be available within 30 minutes of notification to perform angiography and embolization. Kim et al prospectively evaluated the effect of a well-defined protocol for improving the IR response time to meet the ASC-COT criteria after IR activation. ${ }^{5}$ They defined a clear criteria for IR activation, a closed loop electronic feedback system (Pager) for recording activation and response times. The response time was defined as the presence of the IR team (attending, nurse, technician, and anesthesiologist) in the hospital. Utilizing this protocol, they achieved a median response time of 28.5 minutes. Compliance to the ASC-COT criteria was met in $69 \%$ of cases. Compared with the historic cohort, the activation to procedure time dropped from 183 to 72 minutes $(p<0.001)$.

It is very important for interventional radiologists to be involved in the creation and implementation of the institutional protocol in Level I and II trauma centers. It is equally important that the IR team develops an internal operational protocol for meeting the ASC-COT requirement or an internally set guideline based on available resources and avoids delays that impact patient outcomes.

\section{Adult Trauma}

\section{Pelvic Trauma}

Pelvic trauma is a complex condition with a mortality rate as high as 32 to $56 \%{ }^{6,12}$ Patients are usually young with a high overall ISS. Rapid exsanguination in PT can arise from venous (80\%) or arterial $(20 \%)$ source. Disruption of the pelvic rim (pelvic fractures) increases the pelvic volume resulting in limited tamponade contributing to bleeding and hemodynamic compromise. Principle veins involved are the presacral and prevesical veins. Arterial bleeds are less common and are more frequently associated with hemodynamic instability. ${ }^{12}$ Principle arterial sources are the anterior branch of the internal iliac-the pudendal, obturator, and the posterior branches-superior gluteal, and the lateral sacral.

Standardized workup and management protocols in PT are essential to avoid delays. Evaluation of coagulopathy with thromboelastography or rotational thromboelastometry and volume loss with serum lactate and blood gas analysis are performed for all PTs. Chest X-ray and extended focused assessment for sonographic evaluation of the trauma patients are deployed immediately for all unstable patients. CT is the gold standard and recommended in hemodynamically stable patients. CT has a $98 \%$ sensitivity for identifying contrast extravasation. In the absence of extravasation, a hematoma of $\geq 500 \mathrm{~mL}$ indicates the presence of an arterial injury. ${ }^{13,14}$ The application of noninvasive external pelvic compression is recommended as an early strategy to stabilize the pelvic ring and decrease the pelvic volume and thereby the amount of pelvic hemorrhage. Complications include skin ulceration/necrosis due to over tightening or rapid removal of the binder which is not recommended for more than 24 to 48 hours. Resuscitative endovascular balloon occlusion of the aorta (REBOA) has emerged as an alternative to emergent procedural intervention in hemodynamically compromised patients suspected to have pelvic bleeding. REBOA involves the placement of an endovascular balloon in the aorta to occlude the aorta and control the bleeding. The three REBOA zones for positioning the balloon include Zone I (supraceliac), Zone II (pararenal), and Zone III (infrarenal). For most pelvic bleeding, Zone III is preferred. The advantage of this procedure is that it can be performed in the field or in the emergency room. Limitations of the procedure include access to functional femoral arteries and the procedure only temporarily stops the bleeding. Complication includes ischemia-reperfusion organ injury followed by multiple-organ failure. REBOA represents a bridge to intervention technique (surgery/angiography or hybrid procedures).

Another technique to temporize and reduce bleeding complication includes preperitoneal packing (PPP). PPP can be performed in the emergency room. Through a suprapubic midline incision, three laparotomy pads can be placed on each side of the urinary bladder in the retroperitoneal space below the pelvic brim toward the iliac vessels. PPP is effective in controlling bleeding from a venous source which accounts for more than 80 to $90 \%$ of the bleeding source in PT. PPP is a complimentary procedure to angioembolization, as the latter is effective in arterial bleeding. Both these techniques represent different mechanisms of stopping pelvic bleeding.

Angioembolization has been shown to be an effective measure in controlling bleeding in hemodynamically unstable patients with an arterial source of bleeding. ${ }^{6}$ It is important to understand that pelvic angiography and embolization are expected to benefit only a small proportion of patients and should be employed once extrapelvic and nonarterial sources of bleeding are controlled.

Angioembolization in PT is indicated in the following scenarios (-Fig. 1) ${ }^{12,13}$ :

1. Pelvic fractures with hemodynamic instability or signs of ongoing bleeding after nonpelvic sources of bleeding have been excluded and efforts for reducing venous bleeding have been performed such as PPP.

2. Arterial contrast extravasation and the presence of a pelvic hematoma on a CT scan regardless of hemodynamic status.

3. Pelvic fractures in those who have undergone pelvic angiography with or without embolization, who have signs of continued ongoing bleeding after nonpelvic sources have been excluded.

4. Patients older than 60 years with major pelvic fractures regardless of hemodynamic status. 


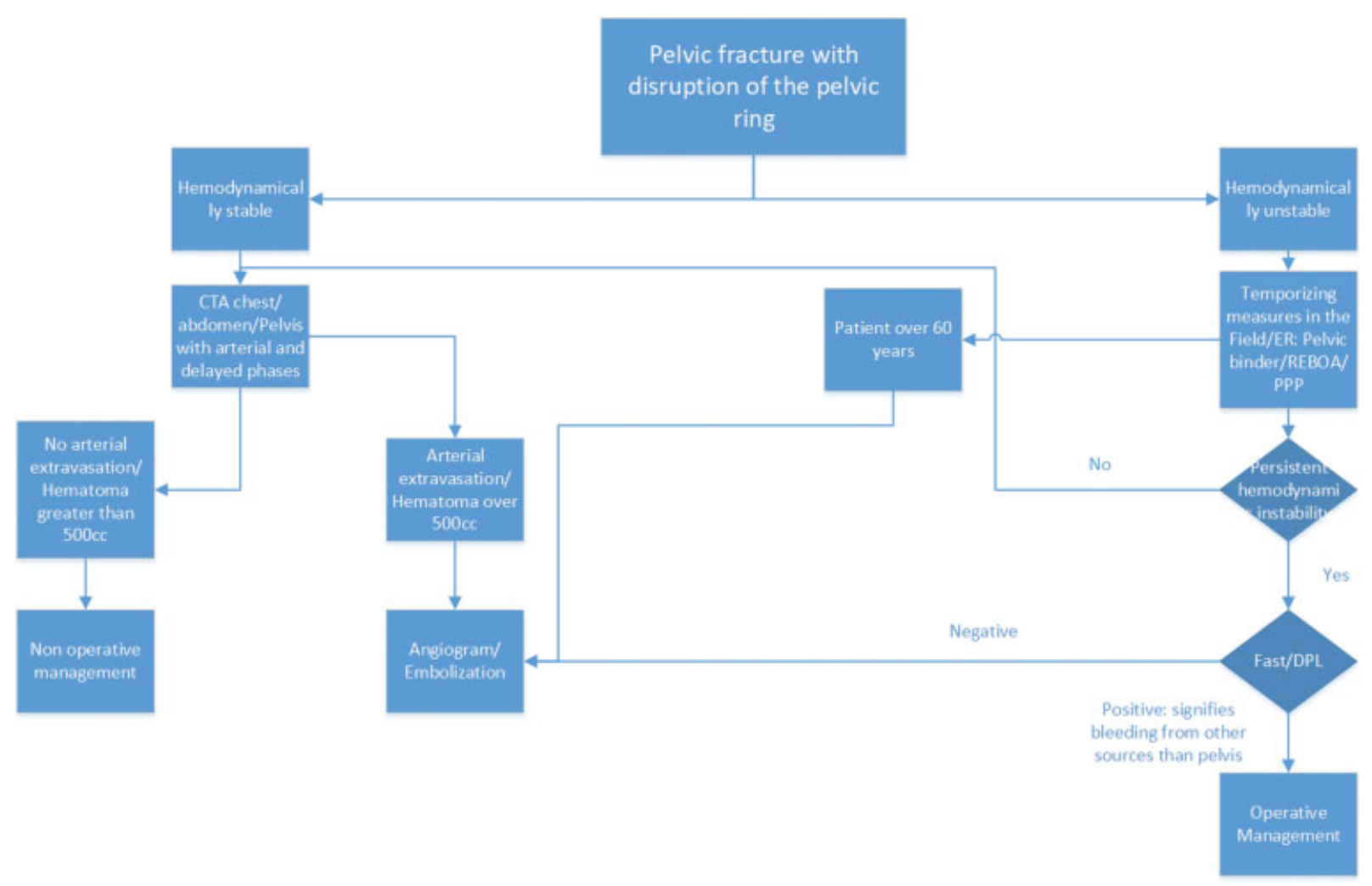

Fig. 1 Algorithm for Management of Pelvic Trauma. CTA, computed tomographic angiography; ER, emergency room; REBOA, resuscitative endovascular balloon occlusion of the aorta; PPP, preperitoneal pelvic packing; FAST, focused assessment with sonography in trauma; DPL, deep peritoneal lavage.

\section{Liver Trauma}

Liver is the most commonly injured organ in abdominal trauma. Road traffic accidents are the most common cause of liver injury with blunt trauma occurring at a rate of $71.1 \%$ and penetrating injury such as stab and gunshot wounds occurring at a rate of $28.9 \%{ }^{15}$ The most common location of liver injury is within the left lobe along the falciform ligament. Surgical operative management (OM) has been replaced by NOM in majority of patients with traumatic liver injury due to the lower complication rates and better outcomes. NOM has been reported to be successful in 50 to $85 \%$ of patients with liver trauma. ${ }^{3}$ The absolute requirements of NOM are hemodynamic stability and absence of other lesions requiring surgery like hollow viscus injury. The American Association for Surgery and Trauma (AAST) classifies the severity of liver injury into six levels (-Table $\mathbf{1}$ ). In a stable patient, the gold standard imaging modality is a CT scan with a specificity and sensitivity of 96 and $90.5 \%$, respectively. Delayed-phase CT helps differentiate active arterial extravasation from contained vascular injuries.

Angioembolization is part of the NOM option for hemodynamically stable patients with evidence of ongoing bleeding with an identified extravasation on CT angiography irrespective of the AAST classification. A meta-analysis looking at the success rate of embolization in hepatic trauma patients reported a 93\% technical success rate. ${ }^{6}$ Complications of angioembolization include hepatic necrosis (15\%), abscess formation (7.5\%), and bile leak $15.2 \%{ }^{16}$ The organ salvage rate after arterial embolization ranges from 86 to
$100 \%{ }^{17}$ Embolization is also considered in patients who are hemodynamically unstable and continue to bleed despite operative intervention. ${ }^{6}$

Angioembolization in liver trauma is indicated in the following scenarios:

1. Hemodynamically unstable/transient response after OM.

2. Arterial contrast extravasation on a CT scan in a hemodynamically stable patient.

\section{Splenic Trauma}

Treatment decision in splenic trauma is based on hemodynamic status. NOM is preferred in patients who are hemodynamically stable without any hollow visceral injury. CT scan is performed in all stable patients. The AAST scores blunt splenic trauma based on CT findings (-Table 2). The injury type (laceration, hematoma, vascular), appearance (capsular, subcapsular, intraparenchymal), and size of the abnormality determine the AAST score (-Table 2 ). For AAST I, II, and III injuries who are hemodynamically stable, the mainstay in management is observation unless there is arterial extravasation/pseudoaneurysm present on the CT. Angioembolization is recommended for the latter and/or in patients who have a AAST IV/V but hemodynamically stable. A recent meta-analysis by Requarth et al showed NOM with angioembolization had an overall failure rate of $15 \%{ }^{18}$ In higher grade IV and V traumas, the failure rate decreases with the addition of angioembolization therapy. ${ }^{19}$ Complications are rare with an incidence of 0 to $7.5 \%$ and include secondary hemorrhage, pseudoaneurysm, and 
Table 1 American Association for Surgery and Trauma Liver Injury grading system

\begin{tabular}{|l|l|l|}
\hline Grade & Injury type & Injury description \\
\hline I & $\begin{array}{l}\text { Hematoma } \\
\text { Laceration }\end{array}$ & $\begin{array}{l}\text { Subcapsular }<10 \% \text { surface } \\
\text { Capsular tear }<1 \mathrm{~cm} \text { parenchymal depth }\end{array}$ \\
\hline II & $\begin{array}{l}\text { Hematoma } \\
\text { Laceration }\end{array}$ & $\begin{array}{l}\text { Subcapsular } 10-50 \% \text { surface area, intraparenchymal }<10 \mathrm{~cm} \text { diameter } \\
1-3 \mathrm{~cm} \text { parenchymal depth, }<10 \mathrm{~cm} \text { length }\end{array}$ \\
\hline III & $\begin{array}{l}\text { Hematoma } \\
\text { Laceration }\end{array}$ & $\begin{array}{l}\text { Subcapsular }>50 \%, \text { surface area or expanding, ruptured subcapsular or parenchymal. Intra- } \\
\text { parenchymal }>10 \mathrm{~cm} \text { diameter } \\
>3 \text { cm parenchymal depth }\end{array}$ \\
\hline IV & Laceration & Parenchymal disruption involving $25-50 \%$ of hepatic lobe \\
\hline V & Laceration & $\begin{array}{l}\text { Parenchymal disruption involving }>75 \% \text { of hepatic lobe } \\
\text { Juxtavenous hepatic injures, retrohepatic vena cava/central major hepatic veins }\end{array}$ \\
\hline VI & Vascular & Hepatic avulsion \\
\hline
\end{tabular}

Table 2 American Association for Surgery and Trauma Splenic Injury grading system

\begin{tabular}{|l|l|l|}
\hline Grade & Injury type & Injury description \\
\hline I & $\begin{array}{l}\text { Hematoma } \\
\text { Laceration }\end{array}$ & $\begin{array}{l}\text { Subcapsular }<10 \% \text { surface } \\
\text { Capsular tear }<1 \mathrm{~cm} \text { parenchymal depth }\end{array}$ \\
\hline II & $\begin{array}{l}\text { Hematoma } \\
\text { Laceration }\end{array}$ & $\begin{array}{l}\text { Subcapsular } 10-50 \% \text { surface area, intraparenchymal }<5 \mathrm{~cm} \text { diameter } \\
1-3 \mathrm{~cm} \text { parenchymal depth not involving a parenchymal vessel }\end{array}$ \\
\hline III & $\begin{array}{l}\text { Hematoma } \\
\text { Laceration }\end{array}$ & $\begin{array}{l}\text { Subcapsular }>50 \%, \text { surface area or expanding, ruptured subcapsular or parenchymal. } \\
\text { Intraparenchymal }>5 \mathrm{~cm} \text { diameter } \\
>3 \text { cm parenchymal depth or involving trabecular vessels }\end{array}$ \\
\hline IV & Laceration & Laceration of the segmental or hilar vessels producing major devascularization (25\% of spleen) \\
\hline V & Laceration & $\begin{array}{l}\text { Completely shatters spleen } \\
\text { Hilar vascular injury which devascularized spleen }\end{array}$ \\
\hline
\end{tabular}

splenic abscesses. ${ }^{20}$ Although NOM is the current choice of treatment, OM is needed when NOM fails, or if the patient is hemodynamically unstable. Even with OM, splenectomy is not always performed as the spleen has a key role in immunologic function. Studies of NOM have shown that the immune function after splenic artery embolization remains intact. 6

Angioembolization in splenic trauma is indicated in the following scenarios:

1. Arterial contrast extravasation, pseudoaneurysm, arteriovenous on a CT scan in a hemodynamically stable patient irrespective of AAST classification.

2. Hemodynamically stable, AAST grades IV and V regardless of the presence of extravasation on CT.

3. Hemodynamically stable with persistent hemorrhage regardless of the CT finding once extrasplenic sources of bleeding have been excluded.

\section{Kidney Trauma}

Renal injury accounts for 1 to $5 \%$ of traumatic injuries ${ }^{21}$ and is classified into five grades by the AAST (-Table 3 ). The most common causes for injury are contusions and superficial laceration (AAST I, II), which are often self-limited. Major grade $\mathrm{V}$ injuries are rare and require surgical intervention, usually a nephrectomy. AAST grades III and IV are most likely to benefit from angioembolization. Conservative NOM is currently used in approximately $80 \%$ of high-grade renal injuries. ${ }^{21}$ Surgical intervention is preferred in cases of hemodynamic instability, multiorgan involvement, urine leaks, or more than $50 \%$ of kidney involvement. ${ }^{6}$

Angioembolization in renal trauma is indicated in the following scenarios:

1. Arterial contrast extravasation, pseudoaneurysm, and arteriovenous fistula on a CT scan in a hemodynamically stable patient.

2. AAST grades III and VI when surgical exploration is not warranted.

\section{Aortic Trauma}

Aortic injury is a life-threating condition that occurs most commonly after sudden deceleration as in motor vehicle accidents and fall from a height. The incidence of traumatic aortic injury (TAI) is low occurring in 0.3 to $1 \%$ of all trauma, but only $20 \%$ of patients survive to reach the hospital. ${ }^{22,23}$ Majority of the TAI occurs in the proximal descending aorta. In the past decade, thoracic endovascular repair (TEVAR) has become the mainstay in the treatment of TAI. TEVAR is associated with increased survival and decreased neurological deficit and spinal cord injury compared with open repair and NOM. ${ }^{24}$ Society of Vascular Surgery classifies TAI into four grades based on the severity of injury (-Table 4). ${ }^{25}$ Emergent TEVAR is recommended in anatomically favorable grade III and IV aortic injuries, while NOM is recommended for grade I and II injuries. 
Table 3 American Association for Surgery and Trauma Kidney Injury grading system

\begin{tabular}{|l|l|l|}
\hline Grade & Injury type & Injury description \\
\hline I & $\begin{array}{l}\text { Hematoma } \\
\text { Contusion }\end{array}$ & $\begin{array}{l}\text { Subcapsular, nonexpanding without parenchymal laceration } \\
\text { Microscopic or gross hematuria. Urological studies are normal }\end{array}$ \\
\hline II & $\begin{array}{l}\text { Hematoma } \\
\text { Laceration }\end{array}$ & $\begin{array}{l}\text { Nonexpanding perirenal hematoma confined to the renal retroperitoneum } \\
<1.0 \mathrm{~cm} \text { parenchymal depth of the renal cortex with no urinary extravasation }\end{array}$ \\
\hline III & Laceration & $>1.0 \mathrm{~cm}$ parenchymal depth of renal cortex w/out collecting system rupture or urinary extravasation \\
\hline IV & $\begin{array}{l}\text { Laceration } \\
\text { Vascular }\end{array}$ & $\begin{array}{l}\text { Parenchymal laceration extending through the renal cortex, medulla, and collecting system } \\
\text { Main renal artery or vein injury with contained hemorrhage }\end{array}$ \\
\hline V & $\begin{array}{l}\text { Laceration } \\
\text { Vascular }\end{array}$ & $\begin{array}{l}\text { Completely shattered kidney } \\
\text { Avulsion of the renal hilum that devascularizes kidney }\end{array}$ \\
\hline
\end{tabular}

Table 4 Society of Vascular Surgery Aortic Injury grading system

\begin{tabular}{|l|l|}
\hline Grade & Aortic injury \\
\hline I & Intimal tear \\
\hline II & Intramural hematoma \\
\hline III & Pseudoaneurysm \\
\hline IV & Rupture \\
\hline
\end{tabular}

\section{Extremity Trauma}

Peripheral vascular injury (PVI) affecting the extremity accounts for 45 to $80 \%$ of all vascular traumas. In general, lower extremities are more often injured than upper extremities. PVIs are graded according to the AAST organ injury scale (-Table 5). ${ }^{26}$ Most patients with significant PVI will need operative intervention to fix conditions other than the vascular injury. Two anatomical locations where endovascular interventions have emerged are for iliac and axillarysubclavian arteries. In both these locations, endovascular repair with stent placement has shown to reduce complication rates compared with open repair. ${ }^{27}$ Embolization to stop hemorrhage in arterial injury should be considered in areas where the embolization would not lead to limb loss.

\section{Pediatric Trauma}

\section{Abdominal Trauma}

Abdominal trauma is present in approximately $25 \%$ of pediatric trauma patients. ${ }^{28}$ Pediatric trauma is usually blunt in nature $(90 \%)$, with the spleen being the most commonly involved organ. ${ }^{29}$ Splenic trauma is especially of concern due to the immunological properties of the spleen, which is particularly important during childhood. Ten percent of all pediatric blunt abdominal trauma involves injury to the kidney. $^{30}$

Abdominal trauma can be characterized by grade of injury based on the 2000 American Pediatric Surgery Association (APSA) guidelines. Management of the patients is based on hemodynamic status rather than grade, as it is safe and more cost-effective. ${ }^{31}$ Diagnosis includes clinical parameters like age-adjusted shock index, imaging findings on focused ab-
Table 5 American Association for Surgery and Trauma Extremity Vascular Injury grading system

\begin{tabular}{|l|l|}
\hline Grade & \\
\hline I & $\begin{array}{l}\text { Digital artery/vein, palmar artery/vein, deep pal- } \\
\text { mar artery/vein, dorsalis pedis/plantar } \\
\text { artery/vein, non-named arterial and venous } \\
\text { branches }\end{array}$ \\
\hline II & $\begin{array}{l}\text { Basilic/Cephalic vein, saphenous vein, radial ar- } \\
\text { tery, ulnar artery }\end{array}$ \\
\hline III & $\begin{array}{l}\text { Axillary vein, superficial/deep femoral vein, pop- } \\
\text { liteal vein, brachial artery, anterior tibial artery, } \\
\text { posterior tibial artery, peroneal artery, tibiopero- } \\
\text { neal trunk }\end{array}$ \\
\hline IV & $\begin{array}{l}\text { Superficial and deep femoral artery, popliteal } \\
\text { artery }\end{array}$ \\
\hline V & Axillary artery, common femoral artery \\
\hline
\end{tabular}

dominal sonography in trauma, contrast-enhanced ultrasound using a second-generation intravenous contrast agent, and $\mathrm{CT}^{31}$ Based on hemodynamic stability, initial management includes fluid boluses of normal saline or Ringer's lactate and transfusion with packed red blood cells. The standard management of solid-organ injury in pediatric patients is nonoperative. More than $96 \%$ of injuries may be managed without surgery. ${ }^{31}$ NOM failure occurs early within the first 48 hours. Reasons for failure include shock, continued hemorrhage (49\%), peritonitis (42\%), pancreatic injury (8\%), and ruptured diaphragm (1\%). ${ }^{31}$ Angioembolization can be used to control bleeding, even though a majority of children with contrast extravasation do not require it. The role of angioembolization is limited to children who are experiencing NOM failure.

\section{References}

1 Rhee P, Joseph B, Pandit V, et al. Increasing trauma deaths in the United States. Ann Surg 2014;260(01):13-21

2 Sauaia A, Moore FA, Moore EE, et al. Epidemiology of trauma deaths: a reassessment. J Trauma 1995;38(02):185-193

3 Coccolini F, Coimbra R, Ordonez C, et al; WSES Expert Panel. Liver trauma: WSES 2020 guidelines. World J Emerg Surg 2020; 15(01):24 
4 Kataoka Y, Minehara H, Kashimi F, et al. Hybrid treatment combining emergency surgery and intraoperative interventional radiology for severe trauma. Injury 2016;47(01):59-63

$5 \mathrm{Kim}$ C, Niekamp A, Pillai AS, et al. Quality improvement project: improving interventional radiology response times for Level I trauma embolization. J Am Coll Radiol 2020;17(06):791-795

6 Padia SA, Ingraham CR, Moriarty JM, et al. Society of Interventional Radiology Position Statement on endovascular intervention for trauma. J Vasc Interv Radiol 2020;31(03):363-369. e2

7 Schwartz DA, Medina M, Cotton BA, et al. Are we delivering two standards of care for pelvic trauma? Availability of angioembolization after hours and on weekends increases time to therapeutic intervention. J Trauma Acute Care Surg 2014;76(01): 134-139

8 Tesoriero RB, Bruns BR, Narayan M, et al. Angiographic embolization for hemorrhage following pelvic fracture: Is it "time" for a paradigm shift? J Trauma Acute Care Surg 2017;82(01):18-26

9 Tanizaki S, Maeda S, Matano H, Sera M, Nagai H, Ishida H. Time to pelvic embolization for hemodynamically unstable pelvic fractures may affect the survival for delays up to $60 \mathrm{~min}$. Injury 2014; 45(04):738-741

10 Black SR, Sathy AK, Jo C, Wiley MR, Minei JP, Starr AJ. Improved survival after pelvic fracture: 13-year experience at a single trauma center using a multidisciplinary institutional protocol. J Orthop Trauma 2016;30(01):22-28

11 Chen HT, Wang YC, Hsieh CC, et al. Trends and predictors of mortality in unstable pelvic ring fracture: a 10-year experience with a multidisciplinary institutional protocol. World J Emerg Surg 2019;14:61

12 Coccolini F, Stahel PF, Montori G, et al. Pelvic trauma: WSES classification and guidelines. World J Emerg Surg 2017;12:5

13 Cullinane DC, Schiller HJ, Zielinski MD, et al. Eastern Association for the Surgery of Trauma practice management guidelines for hemorrhage in pelvic fracture-update and systematic review. J Trauma 2011;71(06):1850-1868

14 Blackmore CC, Cummings P, Jurkovich GJ, Linnau KF, Hoffer EK, Rivara FP. Predicting major hemorrhage in patients with pelvic fracture. J Trauma 2006;61(02):346-352

15 Tarchouli M, Elabsi M, Njoumi N, Essarghini M, Echarrab M, Chkoff MR. Liver trauma: What current management? Hepatobiliary Pancreat Dis Int 2018;17(01):39-44

16 Green CS, Bulger EM, Kwan SW. Outcomes and complications of angioembolization for hepatic trauma: a systematic review of the literature. J Trauma Acute Care Surg 2016;80(03):529-537

17 Fodor M, Primavesi F, Morell-Hofert D, et al. Non-operative management of blunt hepatic and splenic injury: a time-trend and outcome analysis over a period of 17 years. World J Emerg Surg 2019;14:29

18 Requarth JA, D'Agostino RB Jr, Miller PR. Nonoperative management of adult blunt splenic injury with and without splenic artery embolotherapy: a meta-analysis. J Trauma 2011;71(04):898-903, discussion 903

19 Bhullar IS, Frykberg ER, Siragusa D, et al. Selective angiographic embolization of blunt splenic traumatic injuries in adults decreases failure rate of nonoperative management. J Trauma Acute Care Surg 2012;72(05):1127-1134

20 El-Matbouly M, Jabbour G, El-Menyar A, et al. Blunt splenic trauma: assessment, management and outcomes. Surgeon 2016;14(01):52-58

21 Keihani S, Xu Y, Presson AP, et al; Genito-Urinary Trauma Study Group. Contemporary management of high-grade renal trauma: results from the American Association for the Surgery of Trauma Genitourinary Trauma study. J Trauma Acute Care Surg 2018;84 (03):418-425

22 Estrera AL, Gochnour DC, Azizzadeh A, et al. Progress in the treatment of blunt thoracic aortic injury: 12-year single-institution experience. Ann Thorac Surg 2010;90(01):64-71

23 Arthurs ZM, Starnes BW, Sohn VY, Singh N, Martin MJ, Andersen CA. Functional and survival outcomes in traumatic blunt thoracic aortic injuries: an analysis of the National Trauma Databank. J Vasc Surg 2009;49(04):988-994

24 Azizzadeh A, Charlton-Ouw KM, Chen Z, et al. An outcome analysis of endovascular versus open repair of blunt traumatic aortic injuries. J Vasc Surg 2013;57(01):108-114, discussion 115

25 Azizzadeh A, Keyhani K, Miller CC III, Coogan SM, Safi HJ, Estrera AL. Blunt traumatic aortic injury: initial experience with endovascular repair. J Vasc Surg 2009;49(06):1403-1408

26 Kobayashi L, Coimbra R, Goes AMO Jr, et al. AAST - WSES guidelines on diagnosis and management of peripheral vascular injuries. J Trauma Acute Care Surg 2020;89(06):1183-1196

27 Johnson CA. Endovascular management of peripheral vascular trauma. Semin Intervent Radiol 2010;27(01):38-43

28 Lynch T, Kilgar J, Al Shibli A. Pediatric abdominal trauma. Curr Pediatr Rev 2018;14(01):59-63

29 Miller M, Perlick C. Pediatric solid organ injury management: the role of initial hematocrit in lean times. J Emerg Crit Care Med 2019;3(39):1-5

30 Hagedorn JC, Fox N, Ellison JS, et al. Pediatric blunt renal trauma practice management guidelines: collaboration between the Eastern Association for the Surgery of Trauma and the Pediatric Trauma Society. J Trauma Acute Care Surg 2019;86(05):916-925

31 Notrica DM. Pediatric blunt abdominal trauma: current management. Curr Opin Crit Care 2015;21(06):531-537 